\title{
Composição físico-química e potencial para ensilagem do sorgo-de-guiné gigante em seis épocas de semeadura
}

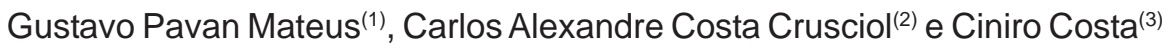

\begin{abstract}
(1)Polo Regional de Desenvolvimento Tecnológico dos Agronegócios do Extremo Oeste (APTA), Caixa Postal 67, CEP 16900-000 Andradina, SP. E-mail: gpmateus@aptaregional.sp.gov.br (2)Universidade Estadual Paulista (Unesp), Fac. de Ciências Agronômicas, Dep. de Produção Vegetal - Agricultura, Caixa Postal 237, CEP 18603-970 Botucatu, SP. E-mail: crusciol@fca.unesp.br (3)Unesp, Fac. de Medicina Veterinária e Zootecnia, Dep. de Melhoramento e Nutrição Animal. E-mail: ciniro@fca.unesp.br
\end{abstract}

Resumo - A ausência de culturas alternativas para o cultivo de outono-inverno é um entrave nos sistemas de produção agrícola, principalmente em regiões de inverno seco. O objetivo deste trabalho foi avaliar a produção de forragem, o potencial para ensilagem e a composição química do sorgo-de-guiné gigante (Sorghum bicolor subsp. bicolor raça guinea), de acordo com a época de semeadura. O delineamento experimental utilizado foi o de blocos casualizados, com quatro repetições e seis épocas de semeadura. Verificou-se antecipação dos estádios de desenvolvimento da planta, à medida que houve atraso na semeadura, em virtude de a espécie apresentar sensibilidade ao fotoperíodo. Semeaduras tardias, apesar de menor produtividade, proporcionaram forragem com características químico-bromatológicas melhores. Diante da boa produção de matéria seca e seu potencial para ensilagem, esse genótipo é uma boa opção a ser utilizada.

Termos para indexação: Sorghum bicolor, produção, poder tampão, fotoperíodo.

\section{Physical-chemical composition and ensiling potential of Giant Guinea sorghum in six different sowing dates}

\begin{abstract}
The lack of alternative crops for fall-winter cultivation is a drawback in the utilization of agricultural production systems, especialy in regions with dry winters. The purpose of this study was to evaluate the potential of Giant Guinea sorghum (Sorghum bicolor subsp. bicolor guinea race) for forage production, ensiling and plant chemical composition, in different sowing dates. The experimental design was a randomized block, with four replications, and six sowing dates. Although sowing was late, Giant Guinea sorghum showed anticipation in development stages due to sensibility to photoperiod; its dry matter production was low, nevertheless the species presented a better quality of forage mass. Due to the considerable capacity of dry matter production and ensiling potential, this species is a good option.
\end{abstract}

Index terms: Sorghum bicolor, yield, capacity power, photoperiod.

\section{Introdução}

A distribuição irregular e a baixa precipitação pluvial são os principais fatores que afetam a produtividade das forrageiras anuais no cultivo de outono-inverno no Brasil. Segundo Nussio (1995), a utilização de silagem tem aumentado, expressivamente, em razão dos ganhos de produtividade animal, principalmente pela prática do confinamento. Por isso, são necessários estudos que permitam a exploração de plantas, cujas exigências possam ser atendidas por baixa disponibilidade hídrica (Pedreira et al., 2003).

De acordo com Magalhães et al. (2000), a planta de sorgo se adapta a uma ampla variação de ambientes e produz razoavelmente bem sob condições desfavorá- veis, em relação à maioria dos outros cereais. Em razão da sua resistência à seca, o sorgo é considerado um dos cultivos mais apropriados às regiões semi-áridas. Suas características lhe conferem ampla adaptação à época de semeadura, que se estende de setembro a março, para as condições do Centro-Sul brasileiro, despertando muito interesse pela semeadura em sucessão às culturas precoces de verão (Zago, 1997).

Entre as forrageiras que podem ser ensiladas, o sorgo tem sido muito explorado por sua maior resistência a veranicos e menor exigência quanto à fertilidade do solo (Dias et al., 2001). Além disso, a silagem de sorgo destaca-se por ser esse um alimento de alto valor nutritivo, que apresenta alta concentração de carboidratos solúveis, essenciais para adequada fermentação lática, al- 
tos rendimentos de matéria seca por unidade de área (Neumann et al., 2002) e, de modo geral, têm apresentado de $85 \%$ a $90 \%$ do valor nutritivo das silagens de milho (Zago, 1997).

De acordo com Heckler (2002), na cultura do sorgo existem genótipos que se comportam de maneira diferenciada, seja na produção de matéria seca, no ciclo vegetativo ou em outras características. Essas características podem afetar diretamente o desempenho dos animais que consomem esse alimento, tornando evidente a necessidade de estudos que conduzam à seleção de híbridos mais adequados aos sistemas de produção animal (Pedreira et al., 2003).

Busca-se caracterizar espécies viáveis para a otimização de sistemas intensivos de pecuária, os quais dependem da produção de silagem de baixo custo e alto valor nutritivo, para que o giro de capital investido seja feito no menor tempo possível (Neumann et al., 2002).

Com relação ao comportamento e utilização do sorgode-guiné, de pericarpo vermelho, conhecido vulgarmente por sorgo-de-guiné gigante (Sorghum bicolor subsp. bicolor raça guinea), as referências são escassas. Sabese que possui crescimento radicular vigoroso, mesmo em solos compactados (Pace et al., 1999), desenvolvimento inicial lento e grande produção de matéria seca, quando manejado no florescimento (Lima et al., 2000).

O objetivo deste trabalho foi avaliar a produção de forragem, o potencial para a ensilagem e a composição química do sorgo-de-guiné gigante, de acordo com a época de semeadura.

\section{Material e Métodos}

O experimento foi instalado na Fazenda Experimental Lageado, pertencente à Faculdade de Ciências Agronômicas, Campus de Botucatu, Unesp, a 22 $2^{\circ} 51$ 'S e $48^{\circ} 26^{\prime} \mathrm{W}$, altitude de $740 \mathrm{~m}$. O clima, conforme a classificação de Köppen, é do tipo Cwa. Os dados meteorológicos coletados no decorrer do experimento estão apresentados na Tabela 1.

Tabela 1. Precipitação acumulada, temperatura mínima e máxima do ar, no período da semeadura à colheita do sorgode-guiné gigante.

\begin{tabular}{|c|c|}
\hline Elemento & Data de semeadura \\
\hline & $25 / 9 \quad 25 / 10 \quad 24 / 11 \quad 22 / 12 \quad 22 / 2 \quad 3 / 4$ \\
\hline Precipitação acumulada (mm) & $1181 \quad 1162 \quad 1011$ \\
\hline Temperatura mínima do ar $\left({ }^{\circ} \mathrm{C}\right)$ & $19,6 \quad 18,6 \quad 15,9$ \\
\hline Temperatura máxima do $\operatorname{ar}\left({ }^{\circ} \mathrm{C}\right)$ & $29,1 \quad 27,525,0$ \\
\hline
\end{tabular}

O solo do local é classificado como Nitossolo Vermelho estruturado, cuja análise química mostrou os seguintes atributos: $\mathrm{pH}\left(\mathrm{CaCl}_{2}\right), 5,1 ; \mathrm{MO}, 24 \mathrm{~g} \mathrm{dm}^{-3} ; \mathrm{H}+\mathrm{Al}$, $38 \mathrm{mmol}_{\mathrm{C}} \mathrm{dm}^{-3}$; $\mathrm{P}$ (resina), $16 \mathrm{mg} \mathrm{dm}{ }^{-3} ; \mathrm{K}^{+}, \mathrm{Ca}^{2+} \mathrm{e} \mathrm{Mg}^{2+}$, 1,$5 ; 31$ e $17 \mathrm{mmol}_{\mathrm{c}} \mathrm{dm}^{-3}$, respectivamente; CTC, $87 \mathrm{mmol}_{\mathrm{C}} \mathrm{dm}^{-3} \mathrm{e} \mathrm{V}, 56 \%$. Realizou-se aplicação de 1,6 t ha ${ }^{-1}$ de calcário (PRNT 75\%), conforme recomendação para a cultura do sorgo no Estado de São Paulo (Cantarella et al., 1997), seguida de uma aração e gradagem de destorroamento.

O delineamento experimental utilizado foi o de blocos ao acaso, com seis tratamentos e quatro repetições. Os tratamentos constituíram-se de seis épocas de semeadura (25/9/2000, 25/10/2000, 24/11/2000, 22/12/2000, 22/2/2001 e 3/4/2001) de sorgo-de-guiné gigante. Cada parcela foi constituída por oito linhas de $20 \mathrm{~m}$ de comprimento, espaçadas em 0,6 m. Nas avaliações, foram consideradas as seis linhas centrais, em que $0,5 \mathrm{~m}$ da extremidade de cada linha de plantas constituiu-se na bordadura, com área útil total de $68,40 \mathrm{~m}^{2}$.

A espécie utilizada foi classificada por Harlan \& De Wet (1972) como Sorghum bicolor subsp. bicolor, raça guinea, que apresenta em sua constituição panículas grandes e abertas, com grãos fortemente duros e vítreos.

No dia anterior a cada semeadura, efetuou-se nova gradagem de nivelamento, para servir também de controle mecânico às plantas daninhas. A operação de semeadura, em todos os tratamentos, ocorreu de forma mecanizada, por meio de semeadora-adubadora, com quatro linhas espaçadas de $0,6 \mathrm{~m}$, a fim de atingir a densidade populacional de 200.000 plantas por hectare. A adubação de semeadura correspondeu à aplicação de $300 \mathrm{~kg} \mathrm{ha}^{-1}$ do fertilizante formulado 8-28-16.

As sementes foram previamente tratadas com fungicida à base de thiram (i.a.), na dose de $140 \mathrm{~g}$ por $100 \mathrm{~kg}$ de sementes. No controle de plantas daninhas aplicou-se, logo após a semeadura, herbicida em préemergência à base de atrazine (i.a.) + simazine (i.a.), na dose de $1.500 \mathrm{~g} \mathrm{ha}^{-1}$ de ambos. A emergência das plântulas ocorreu, de modo geral, oito dias após a semeadura, em todos os tratamentos.

Foram contados os dias desde a emergência das plantas até o florescimento pleno e o estádio de grãos pastosos, nas determinações dos ciclos da planta. Nesse último estádio, avaliou-se a altura da planta, o diâmetro do colmo e o número de internódios, em dez plantas por parcela. 
Plantas coletadas em $2 \mathrm{~m}$ de fileira foram pesadas, imediatamente, para obtenção da matéria verde e, em seguida, procedeu-se a uma amostragem, da qual uma parte foi armazenada em congelador, a $-20^{\circ} \mathrm{C}$, e a outra, secada em estufa de circulação forçada de ar, a $60^{\circ} \mathrm{C}$, até massa constante, para determinação da porcentagem de matéria seca. Avaliou-se a proporção de colmo, folhas e panículas em dez plantas por parcela. Na fração folha, incluíram-se a lâmina e a bainha; a panícula foi separada na inserção da última folha.

A amostra congelada foi utilizada para determinação de teor dos carboidratos solúveis totais, de acordo com a técnica proposta por Dubois et al. (1956). Na amostra seca, quantificou-se a capacidade tampão ao ácido clorídrico, segundo o método de Playne \& McDonald, adaptado por Tosi (1973). Os teores de fibra bruta, extrato etéreo, minerais e proteína bruta foram quantificados de acordo com o método de Silva (1990). O teor de nutrientes digestíveis totais (NDT) foi estimado pela equação de Kearl (1982).

Todos os dados de cada variável determinada foram submetidos à análise de variância. Realizou-se análise de regressão, na qual adotou-se valor $0,30,60,88,150$ e 190 dias para as semeaduras de 25/9/2000, 25/10/2000, 24/11/2000, 22/12/2000, 22/2/2001 e 3/4/2001, respectivamente. A partir dos resultados da análise de regressão, optou-se pela equação mais adequada, levando-se em consideração, primeiramente, o efeito significativo dos modelos obtidos e, em seguida, verificando-se o de melhor ajuste pelo maior valor do coeficiente de determinação $\left(r^{2}\right)$.

\section{Resultados e Discussão}

A antecipação dos estádios de desenvolvimento da planta, com o atraso da semeadura, teve como conseqüência a redução da fase vegetativa, refletindo-se em menor tempo para as plantas entrarem em florescimento (Figura 1). Essa constatação permite inferir que a espécie de sorgo utilizada apresenta sensibilidade ao fotoperíodo, uma vez que, em baixas temperaturas, a tendência é aumentar o ciclo em função da redução do metabolismo da planta (Magalhães et al., 2000), o que não ocorreu neste trabalho. Verificou-se que para as semeaduras de setembro, outubro, novembro e dezembro, o florescimento ocorreu simultaneamente no dia 25 de março, em virtude do decréscimo do comprimento do dia, como constatado também por Paul (1990) e Alagarswamy et al. (1998).
Na semeadura de abril, o período de desenvolvimento foi curto e as plantas atingiram o florescimento 76 dias após a emergência (DAE), em razão de já estarem submetidas ao fotoperíodo indutivo. Porém, esse período não foi inferior ao observado em fevereiro, já que o metabolismo foi menor devido à redução das temperaturas (Tabela 1). Assim, se as temperaturas tivessem permanecido no mesmo patamar de setembro a fevereiro, a redução no período vegetativo, provavelmente, teria sido maior.

O fotoperíodo influenciou o número de dias para as plantas atingirem o florescimento pleno e, conseqüentemente, o estádio de grãos pastosos (Figura 1). Observou-se que, nas semeaduras de setembro, outubro, novembro, dezembro e fevereiro, as plantas atingiram o estádio de grãos pastosos com o mesmo intervalo após o florescimento, ou seja, 31 dias. Já na semeadura de abril, as plantas atingiram o estádio de grãos pastosos 36 dias após o florescimento, provavelmente pelo menor metabolismo, em razão da redução das temperaturas (Tabela 1). Esses resultados corroboram os relatados por Vanderlip \& Reeves (1972), que encontraram período de 25 dias, entre o florescimento e o estádio de grãos pastosos, em uma cultivar de sorgo com ciclo de 100 dias.

Com o atraso da semeadura, o fotoperíodo mais curto acelerou o ciclo biológico das plantas, refletindo-se em menor desenvolvimento, como pode ser constatado pelos resultados de altura de plantas, diâmetro do colmo e número de internódios que atingiram taxas de redução de $67 \%$, $65 \%$ e $77 \%$, respectivamente, quando foram comparadas as semeaduras de setembro e abril (Figura 2).

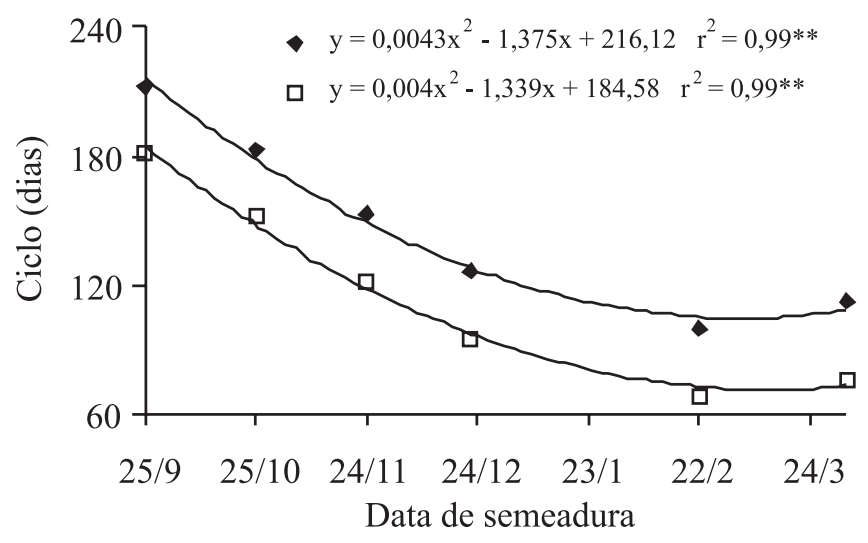

Figura 1. Ciclo da planta de sorgo-de-guiné gigante para atingir o estádio de florescimento ( $\square$ ) e de grãos pastosos ( $\bullet$ ), de acordo com a época de semeadura. 
Por conseguinte, a produção de matéria verde e matéria seca da parte aérea diminuiram linearmente, com o
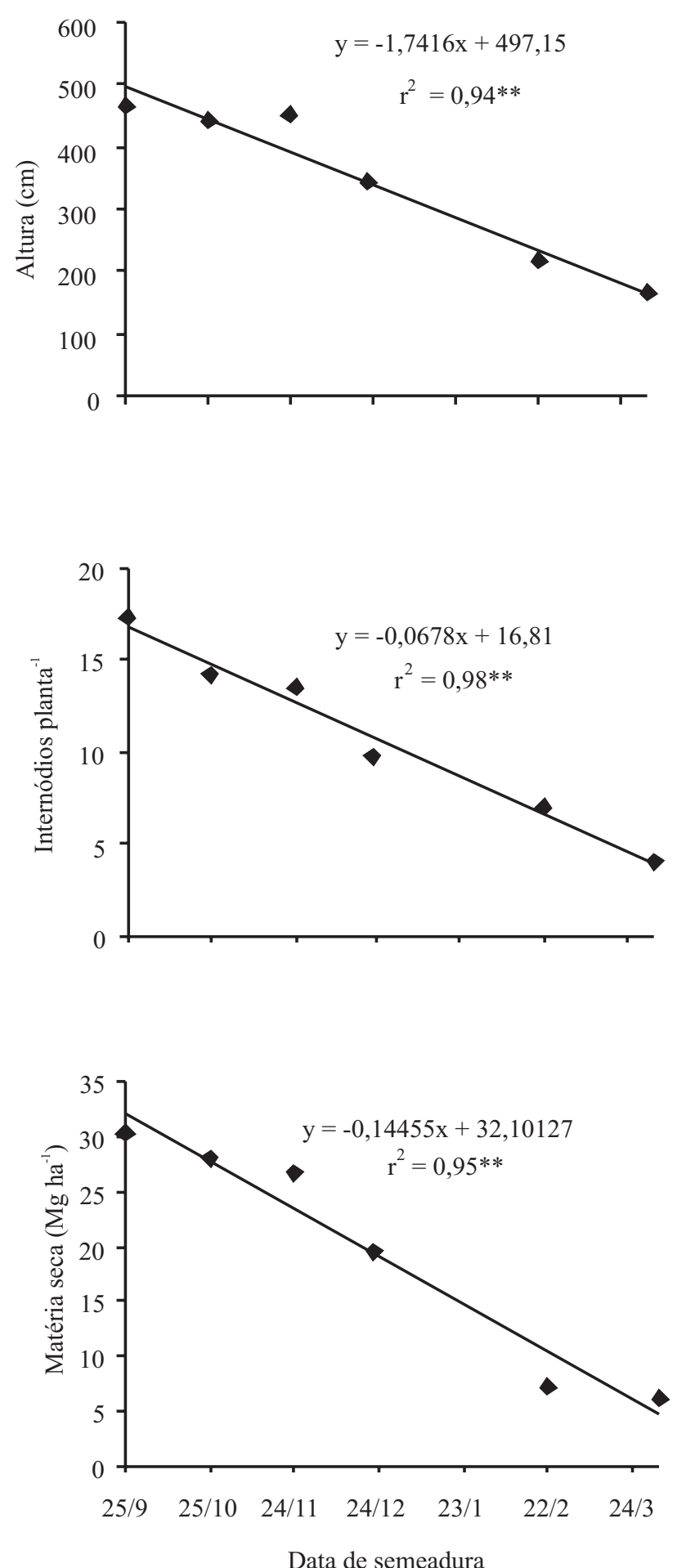

atraso da semeadura (Figura 2). Com exceção de fevereiro e abril, em todas as semeaduras, as produções de
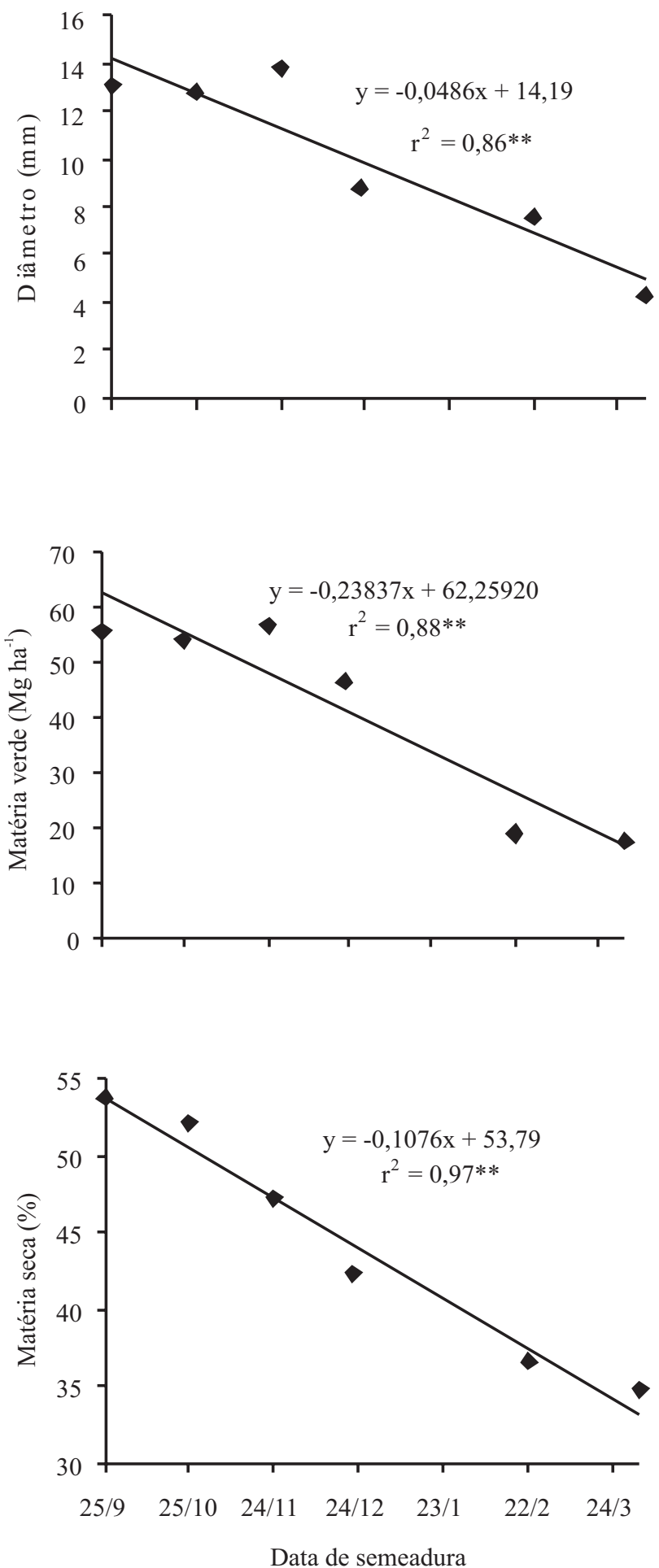

Figura 2. Altura da planta, diâmetro do colmo, número de internódios por planta, produção de matéria verde, produção de matéria seca e porcentagem de matéria seca do sorgo-de-guiné gigante, no estádio de grãos pastosos, de acordo com a época de semeadura. 
matéria verde foram superiores às observadas por Neumann et al. (2002), que constataram produtividade entre 22,7 e 39,6 $\mathrm{Mg} \mathrm{ha}^{-1}$ em híbridos de sorgo. Por sua vez, são inferiores às obtidas por Silva et al. (1990), que variaram de 59 a $75 \mathrm{Mg} \mathrm{ha}^{-1}$. A grande variabilidade de produção na cultura do sorgo foi relatada por Demarchi et al. (1995).

A porcentagem de matéria seca da planta, no estádio de grãos pastosos (Figura 2), sofreu redução com o atraso da semeadura, tendo-se observado valores de $54 \%$ e $33 \%$ nas semeaduras de setembro e abril, respectivamente. Tais resultados evidenciam o avançado processo de senescência das plantas nas primeiras semeaduras, as quais apresentaram colmo muito fibroso e porcentagem considerável das folhas completamente secas. Resultados semelhantes foram observados por Silva et al. (1990) e Valente et al. (1984). Considerandose a recomendação de Demarchi et al. (1995), que apontam teores entre $28 \%$ e $38 \%$ como adequados para ensilagem, somente os materiais semeados em fevereiro e abril seriam ensilados com bons teores de matéria seca. Assim, para não haver comprometimento na conservação do material na forma de silagem, o momento da colheita das plantas poderia ser antecipado, de modo a se adequar o teor de matéria seca, principalmente nas primeiras épocas de semeadura.

A porcentagem de colmo diminuiu linearmente com o atraso da semeadura, e a porcentagem de folhas apresentou comportamento inverso ao colmo (Figura 3). Esses resultados concordam com os de Zago (1997) e estão diretamente relacionados com a altura da planta, ou seja, plantas de porte mais alto atingem maiores produções, no entanto, a porcentagem de colmo aumenta enquanto a de folhas diminui.

A porcentagem de panículas apresentou maior valor na semeadura de fevereiro, o que pode ser explicado pelo menor alongamento dos internódios com o atraso da semeadura (Figura 3). Esse fato não foi constatado na semeadura de abril; isso é explicado, em parte, pelas condições climáticas no florescimento, que propiciaram o aparecimento da doença açucarada do sorgo (Claviceps africana), que causou redução na quantidade de grãos produzidos.

O teor de proteína bruta aumentou linearmente com o atraso da semeadura (Figura 4). Essa resposta pode ser atribuída ao efeito de diluição, já que, nas primeiras semeaduras, verificaram-se maiores produções de matéria seca (Figura 2), o que resultou em menores concentrações de proteína bruta. Também pode ser atribuí- da à alteração física das plantas, uma vez que, à medida que a semeadura atrasou, houve maior participação de folhas e grãos (Figura 3), tendo aumentado a concentração de proteína bruta. Esses resultados concordam com os obtidos por Silva et al. (1990) e Valente et al. (1984). No entanto, os valores observados, com exceção da semeadura de abril, foram inferiores aos obtidos por Pesce et al. (2000), que registraram teor médio de $7,7 \%$, em 20 genótipos de sorgo. De acordo com Flaresso et al. (2000), a silagem de sorgo de boa qualidade deve conter de 7,1\% a $8 \%$ de proteína bruta. Assim, verificase que, somente a partir da semeadura de fevereiro as plantas teriam níveis satisfatórios de proteína bruta.

Os teores de extrato etéreo não se ajustaram à função polinomial, tendo ficado na média com o teor de 2,6\% (Figura 4). Os valores encontrados neste trabalho corroboram os de Chaves (1997), mas foram superiores aos de Neumann et al. (2002), que observaram teores entre $1,51 \%$ a $2,28 \%$. Forragens com maior teor de extrato etéreo (gordura) têm valores mais altos de nutrientes digestíveis totais, pelo fato de a gordura fornecer 2,25 vezes mais energia do que os carboidratos. Assim, é fundamental buscar alimentos energéticos para se conseguir manter a produção animal equivalente ao seu potencial (Chaves, 1997).

Observaram-se aumentos lineares nos valores de teor mineral, à medida que se atrasou a semeadura; verificou-se teor de 3,23\% e 4,82\% nas semeaduras de se-

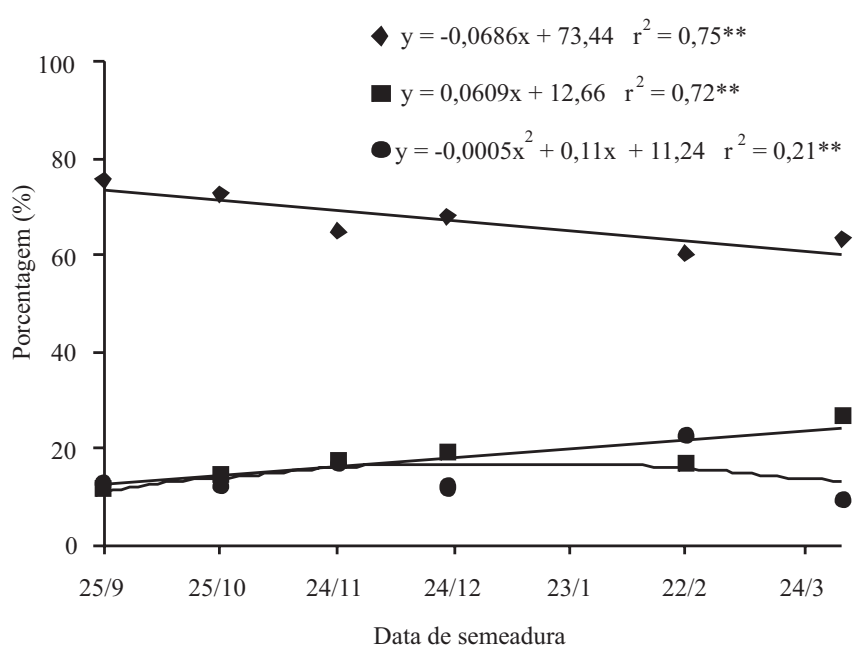

Figura 3. Porcentagem de colmos ( ), folhas $(\square)$ e panículas (•) do sorgo-de-guiné gigante, no estádio de grãos pastosos, de acordo com a época de semeadura. 
tembro e abril, respectivamente (Figura 4). Esses dados são semelhantes aos obtidos por Chaves (1997), que constatou teores entre $3,17 \%$ e 4,77\%. No entanto, com
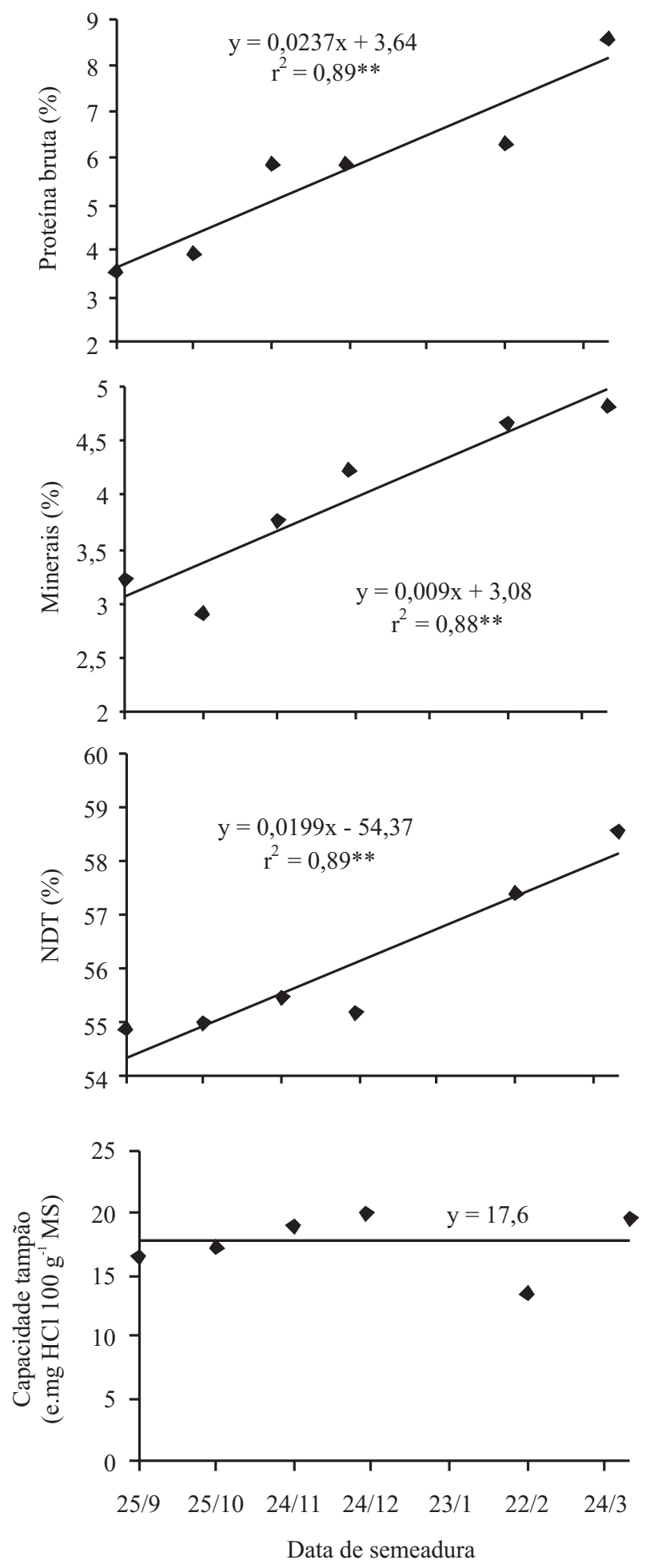

exceção de fevereiro e abril, são inferiores aos observados por Neumann et al. (2002), que alcançaram teores com variação de $4,63 \%$ a $6,29 \%$.
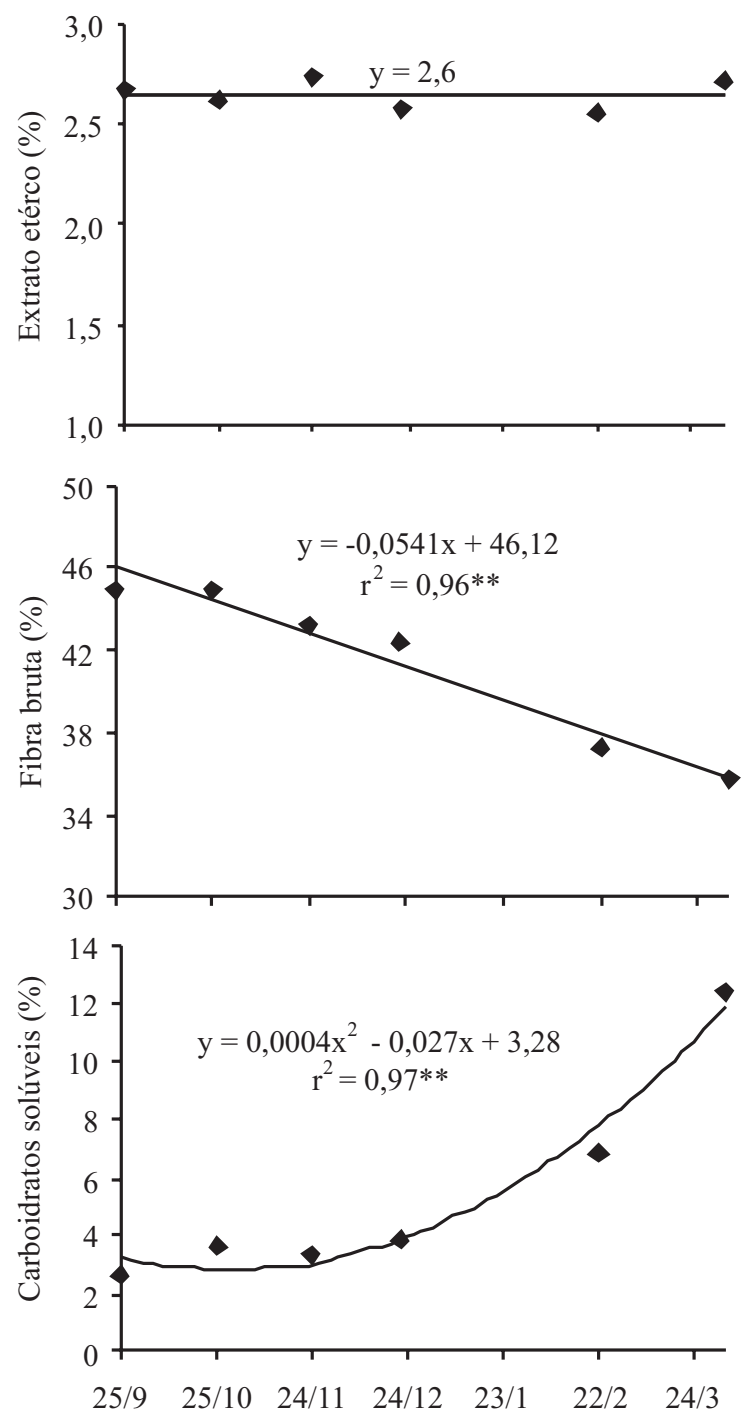

Data de semeadura

Figura 4. Proteína bruta, extrato etéreo, minerais, fibra bruta, nutrientes digestíveis totais (NDT), carboidratos solúveis e capacidade tampão do sorgo-de-guiné gigante, no estádio de grãos pastosos, de acordo com a época de semeadura. 
O teor de fibra bruta decresceu à medida que houve atraso na semeadura (Figura 4); esse resultado pode ser explicado pela menor participação do colmo na estrutura física da planta, uma vez que se verificaram maiores teores de fibra bruta em plantas com elevadas porcentagens de colmos (Figura 3). Os valores obtidos em todas as semeaduras foram superiores aos de Neumann et al. (2002), que observaram teor médio de 31,2\% em quatro híbridos de sorgo.

Os teores de nutrientes digestíveis totais aumentaram linearmente com o atraso da semeadura, com valores de $54,4 \%$ e $58 \%$ nas semeaduras de setembro e abril, respectivamente (Figura 4). Esses teores corroboram o obtido por Flaresso et al. (2000), que foi de 55,3\%, porém são inferiores aos de Pedreira et al. (2003) que alcançaram teores com variação de 63,1\% a $68,4 \%$.

Os teores de carboidratos solúveis aumentaram de forma quadrática com o atraso da semeadura, registrando-se valores de 3,2\% e 12,6\% nas semeaduras de setembro e abril, respectivamente (Figura 4). Os valores obtidos se assemelham aos de Silva et al. (1990), que registraram teores entre $4,5 \%$ e $12,6 \%$. Pesce et al. (2000) ao avaliar 20 genótipos de sorgo verificaram teor médio de 8,5\%. Considerando-se que teores de $6 \%$ a $8 \%$ de substratos fermentáveis são suficientes para desencadear fermentações láticas (Pesce et al., 2000), constata-se que somente as semeaduras de fevereiro e abril apresentariam teores satisfatórios para a ensilagem. No entanto, o teor de carboidratos solúveis não pode ser analisado isoladamente; deve-se verificar também se a capacidade tampão não é elevada (Costa et al., 2000).

Os dados de capacidade tampão da forragem, obtidos em todas as épocas de semeadura (Figura 4), foram semelhantes aos relatados por Costa et al. (2000) para a cultura do milho (17,60 e.mg $\left.\mathrm{HCl} 100 \mathrm{~g}^{-1} \mathrm{MS}\right)$. É possível inferir que todas as épocas de semeadura apresentaram baixa capacidade tampão da forragem, o que evidencia que a espécie estudada apresenta potencial para a ensilagem.

\section{Conclusões}

1. Semeaduras tardias de sorgo-de-guiné gigante reduzem o desenvolvimento da planta, tendo como conseqüência menor produção de forragem e alterações na proporção de seus componentes.

2. Semeaduras tardias de sorgo-de-guiné gigante, em virtude de alterações na sua composição física, proporci- onam forragem de melhor característica químicobromatológica, apesar de menor produtividade.

3. O estádio de grãos pastosos não é o adequado em ensilagem, para semeaduras de setembro a dezembro, devendo-se proceder ao corte mais precocemente.

4. Há viabilidade técnica de utilização do sorgo-de-guiné gigante como cultura de sucessão às culturas tradicionais de verão, porém deverá ser feita uma análise prévia da viabilidade econômica.

\section{Agradecimento}

Ao Conselho Nacional de Desenvolvimento Científico e Tecnógico, pela bolsa concedida ao autor Carlos Alexandre Costa Crusciol.

\section{Referências}

ALAGARSWAMY, G.; REDDY, D.M.; SWAMINATHAN, G. Durations of the period-sensitive and insensitive phases of time to panicle initiation in sorghum. Field Crops Research, v.55, p.1-10, 1998.

CANTARELLA, H.; RAIJ, B. van; SAWAZAKI, E. Cereais: sorgo. Boletim Técnico do Instituto Agronômico de Campinas, n.100, p.66-67, 1997.

CHAVES, A.V. Avaliação de cultivares de sorgo (Sorghum bicolor (L.) Moench) para produção de silagem. 1997. 35p. Dissertação (Mestrado) - Universidade Federal de Viçosa, Viçosa.

COSTA, C.; CRESTE, C.R.; ARRIGONI, M.B.; SILVEIRA, A.C.; ROSA, G.J.M.; BICUDO, S.J. Potencial para ensilagem, composição química e qualidade da silagem de milho com diferentes proporções de espigas. Acta Scientiarum, v.22, p.835-841, 2000.

DEMARCHI, J.J.A.A.; BOIN, C.; BRAUN, G. A cultura do sorgo (Sorghum bicolor (L.) Moench) para a produção de silagens de alta qualidade. Zootecnia, v.33, p.111-136, 1995.

DIAS, A.M.A.; BATISTA, A.M.V.; FERREIRA, M.A.; LIRA, M.A.; SAMPAIO, I.B.M. Efeito de estádio vegetativo do sorgo (Sorghum bicolor (L.) Moench) sobre a composição química da silagem, consumo, produção e teor de gordura do leite para vacas em lactação, em comparação à silagem de milho (Zea mays). Revista Brasileira de Zootecnia, v.30, p.2086-2092, 2001.

DUBOIS, M.; GILLES, K.A.; HAMILTON, J.K.; REDERS, P.A.; SMITH, F. Calorimetric method for determination of sugars and related substances. Analytic Chemistry, n.28, p.350-356, 1956.

FLARESSO, J.F.; GROSS, C.D.; ALMEIDA, E.X. Cultivares de milho (Zea mays L.) e sorgo (Sorghum bicolor (L.) Moench.) para ensilagem no alto vale do Itajaí, Santa Catarina. Revista Brasileira de Zootecnia, v.26, p.1608-1615, 2000.

HARLAN, J.R.; DE WET, J.M.J. A simplified classification of cultivated sorghum. Crop Science, v.12, p.172-176, 1972.

HECKLER, J.C. Sorgo e girassol no outono-inverno, em sistema plantio direto, no Mato Grosso do Sul, Brasil. Ciência Rural, v.32, p.517-520, 2002. 
KEARL, L.C. Nutrient requirements of ruminants in developing countries. Logan, Utah: Utah State University, 1982.

LIMA, E.V.; CRUSCIOL, C.A.C.; LIMA, P.L.; ROSOLEM, C.A. Produção de matéria seca, teores de macronutrientes em plantas de sorgo, milheto e painço na implantação do sistema de plantio direto. In: CONGRESSO NACIONAL DE MILHO E SORGO, 23., 2000, Uberlândia. Resumos expandidos. Sete Lagoas: Embrapa - CNPMS, 2000. 1 CD-ROM.

MAGALHÃES, P.C.; DURAES, F.O.M.; SCHAFFERT, R.E. Fisiologia da planta de sorgo. Sete Lagoas: Embrapa Milho e Sorgo, 2000. 46p. (Circular Técnica, 3).

NEUMANN, M.; RESTLE, J.; ALVES FILHO, D.C.; BRONDANI, I.L.; PELLEGRINI, L.G.; FREITAS, A.K. Avaliação do valor nutritivo da planta e da silagem de diferentes híbridos de sorgo (Sorghum bicolor (L.) Moench.). Revista Brasileira de Zootecnia, v.31, p.293301, 2002.

NUSSIO, L.G. Milho e sorgo para produção de silagem. In: PEIXOTO, A.M.; MOURA, J.C.; FARIA, V.P. Volumosos para bovinos. Piracicaba: Fundação de Estudos Agrários Luiz de Queiroz, 1995. p.75-178.

PACE, L.; FOLONI, J.S.S.; TIRITAN, C.S.; ROSOLEM, C.A. Desenvolvimento radicular e acúmulo de nutrientes em adubos verdes de verão submetidos à compactação do solo. In: CONGRESSO BRASILEIRO DE CIÊNCIA DO SOLO, 27, 1999, Brasília. Resumos expandidos. Brasília: Embrapa - CPAC, 1999. 1 CD-ROM.

PAUL, C.L. Aspectos fisiológicos del crecimiento y desarollo del sorgo. In: PAUL, C.L. Agronomía del sorgo. Patancheru: ICRISAT, 1990. p.43-68.
PEDREIRA, M.S.; REIS, R.A.; BERCHIELLI, T.T.; MOREIRA, A.L.; COAN, R.M. Características agronômicas e composição química de oito híbridos de sorgo (Sorghum bicolor (L.) Moench). Revista Brasileira de Zootecnia, v.32, p.1083-1092, 2003.

PESCE, D.M.C.; GONÇALVES, L.C.; RODRIGUES, J.A.S.; RODRIGUEZ, N.M.; BORGES, I. Análise de vinte genótipos de sorgo (Sorghum bicolor (L.) Moench), de portes médio e alto, pertencentes ao ensaio nacional. Revista Brasileira de Zootecnia, v.29, p.978-987, 2000.

SILVA, D.J. Análise de alimentos: métodos químicos e biológicos. 2.ed. Viçosa: Universidade Federal de Viçosa, 1990. 165p.

SILVA, J.F.C.; OBEID, J.A.; FERNANDES, W.; GARCIA, R. Idade de corte do sorgo Santa Eliza (Sorghum vulgare Pers.), para silagem. I. Produção e característica das silagens. Revista da Sociedade Brasileira de Zootecnia, v.19, p.98-105, 1990.

TOSI, H. Ensilagem de gramíneas tropicais sob diferentes tratamentos. 1973. 107p. Tese (Doutorado) - Faculdade de Ciências Médicas e Biológicas de Botucatu, Botucatu.

VALENTE, J.O.; SILVA, J.F.C.; GOMIDE, J.A. Estudo de duas variedades de milho (Zea mays L.) e de quatro variedades de sorgo, para silagem.1.Produção e composição do material ensilado e das silagens. Revista da Sociedade Brasileira de Zootecnia, v.13, p.67-73, 1984.

VANDERLIP, R.L.; REEVES, H.E. Growth stages of sorghum (Sorghum bicolor (L.) Moench). Agronomy Journal, v.64, p.13-16, 1972.

ZAGO, C.P. Utilização do sorgo na alimentação de ruminantes. In: Manejo cultural do sorgo para forragem. Sete Lagoas: EmbrapaCNPMS, 1997. p.9-26 (Circular Técnica, 17). 